\title{
SUPPORTING VIRTUAL MOBILITY SKILLS IN A MOOC: PRELIMINARY RESULTS
}

\author{
Antonella Poce, Francesca Amenduni, Maria Rosaria Re, Carlo De Medio, \\ Roma Tre University, Department of Educational Sciences, Italy
}

\section{Abstract}

In the last years, the concept of Virtual Mobility has receiving a growing attention from educational policy makers and institutions, because it has the potential to make more accessible and effective students and teachers mobility in Higher Education. Virtual Mobility could be defined as institutional ICT-supported activities that trigger or facilitate international collaborative experiences in the context of teaching and/or learning. Despite the interest, there is still a few empirical researches regarding actual effectiveness of Virtual Mobility implementation and which technological solutions could be adopted. The present paper describes a research project aimed at designing an Open and Accessible Virtual Mobility Massive Open Online Course, by involving students and teachers from six European countries and higher education institutions. 716 participants completed and assessed the Open Virtual Mobility MOOC. Participants expressed a positive evaluation of different MOOCs features: (a) Badges; (b) Technical features; (c) Gamification. Four out of eight MOOCs obtained the highest evaluation: (a) Collaborative learning; (b) Autonomy-drive learning; (c) Open-mindedness; (d) Intercultural skills. Future research trajectories would be described.

\section{Introduction}

Many institutional mission statements and national higher education strategies aim to prepare students to live in a globalized world in which they are being challenged to become global citizens (Teichler, 2004). The strategies to achieve the internationalization goal in higher education have been changed their nature in recent years. Among these, virtual mobility experience and projects have been developed to complement or substitute for physical mobility (de Wit \& Hunter, 2016). Virtual mobility initiatives were indicated as one of the cost-effective ways to increase the access to educational mobility by Maastricht message in 2009 (ICDE Executive Committee, EADTU Executive Committee, 2009). According to the European Commission, youth mobility and academic mobility can foster 
a genuine European area of knowledge and contribute to the competitiveness of the European economy.

Despite the growing acknowledged of Virtual Mobility, only a few researches have investigated the impact of Virtual Mobility initiatives on participants, and most of them includes small scale studies (Hilliard, 2004; Frydenberg \& Andone, 2010; Costa \& Balula, 2014; Poce, Amenduni, Re, \& De Medio, 2020). A large-scale study was conducted by Poulová, Černá, and Svobodová (2009) with a group of more than 2000 participants in a time-frame project of four years to assess the efficiency of a Virtual Mobility program that involved 8 European Universities. They found out that less than $50 \%$ of students who started the program passed their subject and gained the final credit. From the analysis of a survey, they identified different reasons of the students' drop-out, included a lack of selfregulated students' skills, especially in terms of time management and study-goal settings. Although more research is necessary to understand what are the most important variables of a successful Virtual Mobility experience, the results of the previous experience suggest the critical role of participants' transversal skills in Virtual Mobility Experience. Rajagopal and Firssova (2018) recently identified 8 transversal knowledge and skills necessary to be involved in a Virtual Mobility experience, by applying a group concept mapping methodology and involving 49 experts in the domains of virtual mobility: (a) Intercultural Skills; (b) Collaborative learning; (c) Autonomy-driven learning; (d) Networked Learning; (e) Media and digital literacy; (f) Active self-regulated learning; (g) Open mindedness; (h) Knowledge of Virtual Mobility and Open Education.

A Massive Open Online Course (MOOC) aimed at developing the eight transversal skills identified by Rajagopal and Firssova (2018) has been developed by the authors of the paper in the context of the Erasmus+ project "OpenVM: Opening Education for Developing, Assessing and Recognising Virtual Mobility Skills in Higher Education”. The project is based on the idea that VM could be enhanced by adopting the principles of open education in the Open Virtual Mobility MOOC, a massive open online course aimed at developing Virtual Mobility Skills in higher education students (Buchem et al., 2018; Buchem, Tur, \& Urbina, 2018). The need to adopt a non-formal approach to virtual mobility based on the principles of Open Education has been recognized by many authors (Tovar \& Lesko, 2014; Wilson et al., 2011). Open education is understood as a mode of undertaking education using digital technologies and providing alternative, less restrictive access routes to formal and non-formal education. This broad perspective enables a comprehensive view, thus encompassing, for instance, Open Educational Resources (OERs), MOOCs, and recognition of open learning. MOOCs are now being considered and applied by many institutions around the world as a valid internationalization instrument (Knight, 2014). However, Amirault and Visser (2010) show that virtual program offerings do not 
automatically cross borders, nor result in the same effects everywhere. The context of the partnership of the European Project allows to involve students from 6 European countries and institutions: Roma Tre University (Italy); Beuth University (Germany); Universitatea Politehnica Timisoara (Romania); Universitat de les Illes Balears (UIB), AUNEGE, Open Universiteit - Welten Instituut (Netherlands).

\section{The Open VM MOOC design and structure}

The aim of the Open VM MOOC is to help educators and students developing a defined set of VM skills and applying them to Virtual Mobility programs, actions and activities in various academic disciplines (Yuan \& Powell, 2013). The MOOC Canvas (Alario-Hoyos, Pérez-Sanagustín, Delgado-Kloos, 2013) was adopted to support the design, and to promote discussions between the different project partners involved in the creation of a MOOC. In line with the features proposed by Bates (2015), the OpenVM MOOC was conceived in conformity with the xMOOC definition.

Eight areas have been identified (Rajagopal \& Firssova, 2018) as main contents for the OpenVM MOOC: (a) Intercultural Skills; (b) Collaborative learning; (c) Autonomy-driven learning; (d) Networked Learning; (e) Media and digital literacy; (f) Active self-regulated learning; (g) Open mindedness; (h) Virtual Mobility Knowledge. For each area, a miniMOOC was created. Three levels are then proposed for each miniMOOCs: (a) foundation level: focused on knowledge acquisition; (b) intermediate level: focused on knowledge application in a collaborative learning environment; (c) advanced level: focused on self-reflection and meta-reflection. Each miniMOOC has a pre-assessment activity: participants are required to fill in a quiz and, according to the score they obtain, they will be directed to the foundation level, intermediate level or advanced level. Each combination between the level and the miniMOOC is defined a subMOOC. Thus, the OpenVM MOOC is composed by 24 subMOOC, 8 miniMOOCs for 3 levels (Figure 1). Each subMOOC has different forms of assessment and tasks. More specifically, in the foundation and in the intermediate levels there are mainly quizzes (e.g. multiple choices, true or false and drag and drop exercises), whilst in the advanced level there are also e-portfolio and peerassessment activities. In the intermediate level, there are also collaborative learning activities, supported by the use of the Matching tool, an algorithmic solution for building learning groups (Konert, Burlak, \& Steinmetz, 2014). At the end of each subMOOC, participants obtain a badge that certifies the skills acquired in that specific subMOOC.

\section{The pilot-phase iterations}

The pilot-phase was realized in order to understand how OpenVM MOOCs participants assessed the quality of the MOOC main components. We tried to answer the following research questions: 
- To which extent students enjoyed the OpenVM MOOC design and its main components?

- Are there any differences in the assessment of the 8 miniMOOCs and subMOOCs?

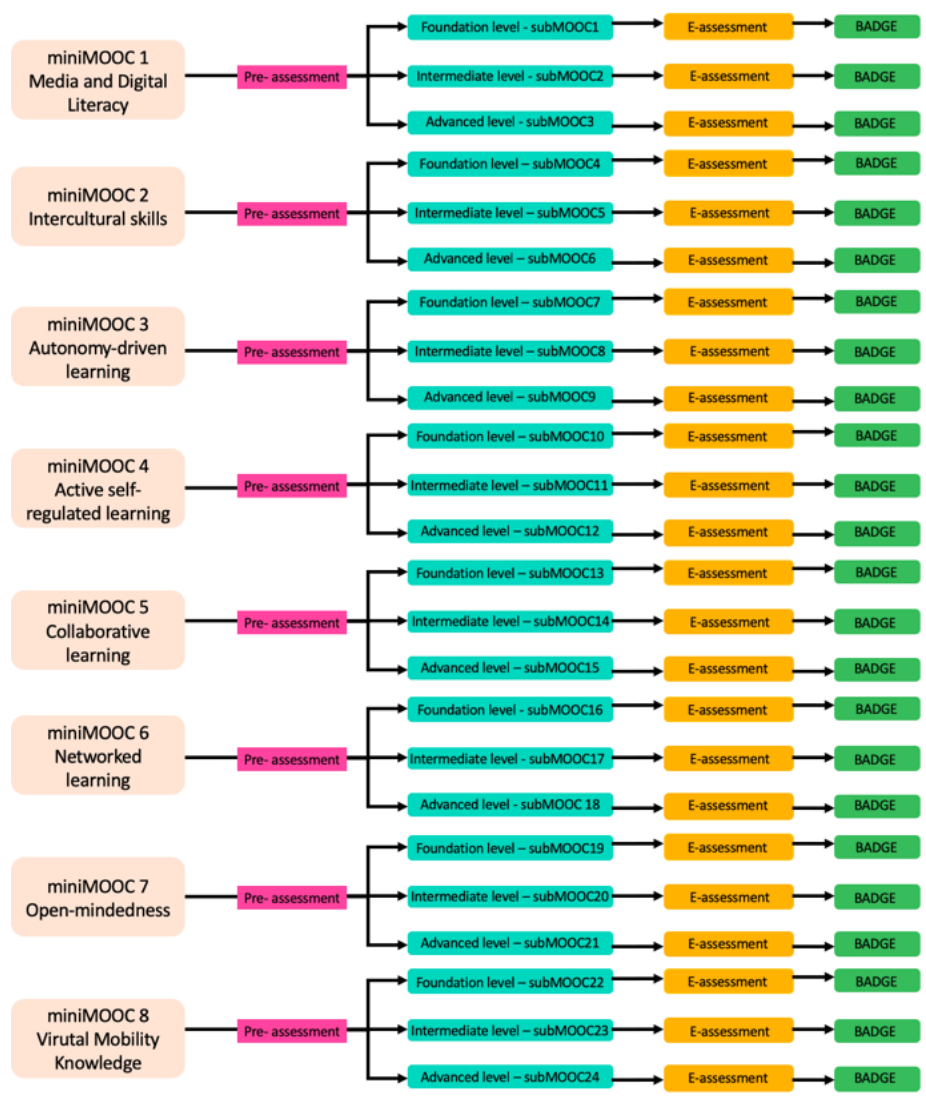

Figure 4. The OpenVM MOOC structure

At the end of the subMOOC, MOOC participants $(\mathrm{N}=716)$ were invited to fill in an online questionnaire, designed by the authors and implemented by other involved partners. OpenVM Evaluation Questionnaire is organised in eight sections. In all eight sections participants were required to express their level of agreement with a set of statements related to specific MOOC design elements on a Likert scale from 1 - strongly disagree to 5 - totally agree. OpenVM Evaluation Questionnaire was created using a Google Module and encompasses eight sections:

1. Personal details: age, gender, affiliation and role. In this section participants are required to say which of the eight mini-MOOCs they are assessing;

2. Questions regarding the overall MOOC design: learning experience, quality of content instruction and support for learning;

3. Questions regarding digital credentials and meaningful gamification: quality of design, motivation, engagement and possibilities of choice;

4. Questions regarding technical aspects: use and usability; 
5. Questions regarding the foundation level of a mini-MOOC: duration, language, content, use of multimedia;

6. Questions regarding the intermediate level of a mini-MOOC: extending questions from the foundation level by questions related to the matching tool and group formation activity, which are specific design elements used at this level;

7. Questions regarding the advanced level of a mini-MOOC: extending questions from the foundation and intermediate levels by questions related to e-portfolio and peerassessment activities, which are specific design elements at this level;

8. Questions related to the investigation about the extent to which MOOCs supported self-regulated learning. In this section participants are required to answer also to open-ended questions.

Descriptive statistics (average, standard deviation, frequencies) were calculated in order to answer to the abovementioned research questions

\section{Results}

716 ( $\mathrm{F}=498 ; \mathrm{M}=215$; Not specified = 3) participants took part in the pilot-phase. Most of the participants were university students and only 14 teachers participated in the survey. As shown in Figure 2, 27\% of participants participated and assessed the MOOC "Active Self-regulated Learning", followed by Media and Digital Literacy (22\%), "Openmindedness" (15\%), "Intercultural Skills” (14\%), "Networked Learning” (7\%), “Autonomydrive learning" (6\%), "Collaborative Learning" (5\%) and "Open Education and Virtual Mobility”. In addition, $92 \%$ of participants took part in the foundation level, $51.6 \%$ in the intermediate level and $30.6 \%$ in the advanced level in one of the 8 miniMOOCs.

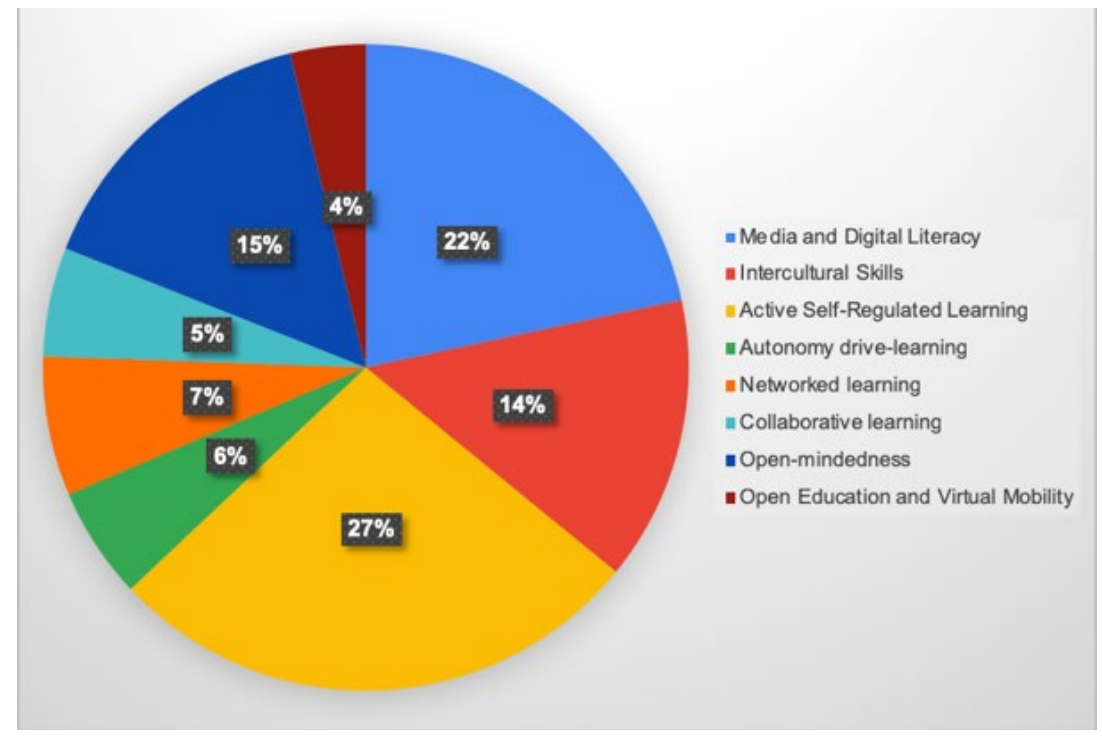

Figure 2. Percentage of participants who attended each miniMOOC 
The results of the OpenVM MOOC evaluation and its main components are presented in Table 1 . The general evaluation of the MOOCs quality was quite positive. The average score for each MOOC is always higher than 3.5 out of 5 points (we used a Likert Scale from 1 to 5 , where the median is 3 ). Also, the general evaluation of the badges was quite positive. The average score for badge is always higher than 3.5 out of 5 points. The general evaluation of the gamification features was still satisfactory because the average score was more than 3. However, it was lower than the technical features evaluation of the MOOCs was quite positive. The average score for each MOOC is always higher than 3.5 out of 5 points and the total average was 3.79. skills. From a general overview we can conclude that four MOOCs at the moment were the best assessed: (a) Collaborative learning; (b) Autonomy-drive learning; (c) Open-mindedness; (d) Intercultural skills.

\section{Discussion and conclusive remarks}

In the context of the Erasmus + Open Virtual Mobility, a Massive Open Online Course (MOOC) aimed at developing the eight transversal skills identified by Firssova and Rajagopal (2018) has been developed. The present study describes the assessment results collected by 716 participants who participated in a pilot phase from September to December 2019. Participants expressed a positive evaluation of different MOOCs features: (a) Badges; (b) Technical features; (c) Gamification. Four out of eight MOOCs obtained the highest evaluation: (a) Collaborative learning; (b) Autonomy-drive learning; (c) Openmindedness; (d) Intercultural skills. Future research would be necessary to understand the reasons why these four MOOCs are preferred compared to the other. One possible explanation is that the other MOOCs, specifically the Media and Digital Literacy MOOC, the Networked MOOC and the Open Education and Virtual Mobility are based not only on transversal skills but also on digital and technological skills and they could be considered more difficult. In addition, the MOOCs "Collaborative learning, Autonomy-drive learning" and "Open-mindedness" were not formally introduced by University teachers partner but they were chosen spontaneously by the participants. This could indicate that they were more motivated and interested in the topic of the MOOCs compared to the participants who were formally invited to follow a specific MOOC chosen a priori by the teacher. In order to better understand the impact of the MOOC on the student's experience, it would be necessary triangulate different sources of information. In future research, we are going to integrate the survey results with analytics collected by the platform. 
Table 1: The results of the OpenVM MOOC evaluation and its main components

\begin{tabular}{|c|c|c|c|}
\hline \multicolumn{4}{|c|}{ General evaluation of the MOOCs } \\
\hline & Average & $\mathrm{N}$ & SD \\
\hline Networked learning & 3.5945 & 50 & 1.02593 \\
\hline Media and Digital Literacy & 3.6938 & 155 & 0.65947 \\
\hline Collaborative learning & 3.7203 & 39 & 0.72619 \\
\hline Active Self-Regulated Learning & 3.7381 & 194 & 0.6769 \\
\hline Open-Education and Virtual Mobility & 3.7542 & 27 & 0.61802 \\
\hline Average & 3.7689 & 716 & 0.72937 \\
\hline Open-mindedness & 3.8182 & 109 & 0.769 \\
\hline Autonomy drive-learning & 3.8477 & 40 & 0.72797 \\
\hline Intercultural Skills & 3.9661 & 102 & 0.71558 \\
\hline \multicolumn{4}{|c|}{ Badge evaluation } \\
\hline Active Self-Regulated Learning & 3.5351 & 194 & 0.78093 \\
\hline Networked learning & 3.56 & 50 & 1.06904 \\
\hline Media and Digital Literacy & 3.591 & 155 & 0.84741 \\
\hline Intercultural Skills & 3.6922 & 102 & 0.76853 \\
\hline Open-mindedness & 3.7193 & 109 & 0.84989 \\
\hline Collaborative learning & 3.7385 & 39 & 0.83874 \\
\hline Autonomy drive-learning & 3.93 & 40 & 0.72402 \\
\hline \multicolumn{4}{|c|}{ Gamification features evaluation } \\
\hline Networked learning & 3.18 & 50 & 0.94868 \\
\hline Collaborative learning & 3.2487 & 39 & 0.69995 \\
\hline Media and Digital Literacy & 3.2613 & 155 & 0.66189 \\
\hline Active Self-Regulated Learning & 3.2964 & 194 & 0.62216 \\
\hline Open Education and Virtual Mobility & 3.3148 & 27 & 0.6125 \\
\hline Average & 3.3226 & 716 & 0.68037 \\
\hline Open-mindedness & 3.3917 & 109 & 0.69949 \\
\hline Autonomy drive-learning & 3.41 & 40 & 0.68605 \\
\hline Intercultural Skills & 3.4578 & 102 & 0.63315 \\
\hline \multicolumn{4}{|c|}{ Technical features evaluation } \\
\hline Open Education and Virtual Mobility & 3.5704 & 27 & 0.66957 \\
\hline Networked learning & 3.6449 & 49 & 1.09412 \\
\hline Media and Digital Literacy & 3.6768 & 151 & 0.8339 \\
\hline Active Self-Regulated Learning & 3.7403 & 191 & 0.71642 \\
\hline Average & 3.7946 & 704 & 0.8078 \\
\hline Collaborative learning & 3.8378 & 37 & 0.78717 \\
\hline Autonomy drive-learning & 3.88 & 40 & 0.77499 \\
\hline Open-mindedness & 3.9 & 108 & 0.83184 \\
\hline Intercultural Skills & 4.0436 & 101 & 0.74222 \\
\hline
\end{tabular}




\section{References}

Amirault, R. J., \& Visser, Y. L. (2010). The impact of e-learning programs on the internationalization of the university. New York, NY: Nova Science Publishers.

Bruhn, E. (2016). Towards a framework for virtual internationalization. Forging new pathways of research and innovation in open and distance learning.

Buchem, I., Konert, J., Carlino, C., Casanova, G., Rajagopal, K., Firssova, O., \& Andone, D. (2018). Designing a Collaborative Learning Hub for Virtual Mobility Skills: Insights from the European Project Open Virtual Mobility. In P. Zaphiris \& A. Ioannou (Eds.), Learning and Collaboration Technologies. Design, Development and Technological Innovation: $5^{\text {th }}$ International Conference, LCT 2018, Held as Part of HCI International 2018, Las Vegas, NV, USA, July 15-20, 2018, Proceedings, Part I (1 ed., pp. 350-375). (Lecture Notes in Computer Science; Vol. 10924). Cham: Springer International Publishing AG. https://doi.org/10.1007/978-3-319-91743-6_27

Buchem, I., Tur, G. \& Urbina, S. (2018). Quality assurance for attainment, assessment and recognition of virtual mobility skills in context of open education. QA Framework in the Open Virtual Mobility project. Paper presented at Edulearn Conference 2-4 July 2018. doi: 10.21125/edulearn.2018.0318

Costa, N., \& Balula, A. (2014). Virtual mobility and learning for PhD students of six European countries-students' programme evaluation. Profesinis rengimas: tyrimai ir realijos, 25, 178-188.

de Wit, H., \& Hunter, F. (2016). Trends, issues and challenges in internationalisation of higher education: Where have we come from and where are we going? In S. McGrath \& Q. Gu (Eds.), Routledge Handbook of International Education and Development.

Frydenberg, M., \& Andone, D. (2010). Two Screens and an Ocean: Collaborating across Continents and Cultures with Web-Based Tools. Information Systems Education Journal, 8(55), n55.

Hilliard, A. (2004, January). Outline and Evaluation of a Joint European and Canadian Virtual Mobility: e-Learning Project. Proceedings of the ECEL2006-5th European Conference on e-Learning: ECEL2006, 163. Academic Conferences Limited.

ICDE Executive Committee, EADTU Executive Committee. (2009). Maastricht Message. From the M-2009 World Conference. $23^{\text {rd }}$ ICDE World Conference and the 2009 EADTU Annual Conference. Retrieved from http://www.eadtu.nl/files/Maastricht\%20Message.pdf 
Knight, J. (2014). Three generations of crossborder higher education: New developments, issues and challenges. Internationalisation of Higher Education and Global Mobility, 43-58.

Konert, J., Burlak, D., \& Steinmetz, R. (2014, September). The group formation problem: an algorithmic approach to learning group formation. Proceedings of the European Conference on Technology Enhanced Learning, 221-234. Springer, Cham.

Poce, A., Amenduni, F., Re, M. R., \& De Medio, C. (2020). Assessing a MOOC users experience in a virtual mobility project: preliminary results for quality enhancement. Italian Journal of Educational Technology, 28(1). https://doi.org/10.17471/2499$4324 / 1126$

Poulová, P., Černá, M., \& Svobodová, L. (2009). University Network? Efficiency of Virtual Mobility. Proceedings of the $5^{\text {th }}$ WSEAS/IASME International Conference on Educational Technologies (EDUTE09), 87-92.

Rajagopal, K., \& Firssova, O. (2018, April). Virtual Mobility in the context of Open Education: re-establishing the boundaries. Proceedings of the Open Education Global Conference 2018: Transforming education through open approaches.

Teichler, U. (2004). The changing debate on internationalization of higher education. Higher Education, 48, 5-26.

Tovar Caro, E., \& Lesko, I. (2014). Analysis of successful modes for the implementation and use of Open Course Ware (OCW) \& Open Educational Resources (OER) in Higher Education. The Virtual Mobility Case. RIED - Revista Iberoamericana de Educación a Distancia, 17(1), 131-148. doi: 10.5944/ried.17.1.11577

Wilson, G., Abbott, D., De Kraker, J., Salgado Perez, P., Scheltinga, C., \& Willems, P. (2011). 'The lived experience of climate change': creating open educational resources and virtual mobility for an innovative, integrative and competence-based track at Masters level. International Journal of Technology Enhanced Learning, 3(2), 111-123.

\section{About the Authors}

A. Poce coordinated the research presented in this paper. Research group is composed by the authors of the contribution that was edited in the following order: A. Poce (Introduction, Discussion and Conclusive Remarks) F. Amenduni (The OpenVM design structure), M.R. Re (The pilot phase iterations), C. De Medio (Results).

\section{Acknowledgements and Disclaimer}

This paper is based on the joint work and research conducted by partner organizations in the Erasmus+ Project Open Virtual Mobility, Cooperation for Innovation and the 
Exchange of Good Practices, Strategic Partnerships for Higher Education, Project Number 2017-1-DE01-KA203-003494 (https://www.openvirtualmobility.eu). The creation of these resources has been (partially) funded by the ERASMUS+ grant program of the European Union under grant no. 2017-1-DE01-KA203-003494. Neither the European Commission nor the project's national funding agency DAAD are responsible for the content or liable for any losses or damage resulting from the use of these resources.

The project is coordinated by Beuth University which contributed to the assessment pilot phase, presented here, drafting the questionnaire administered with the first group of MOOC users. Data collected are described below. 